\title{
A nested circulation model for the North Aegean Sea
}

\author{
V. Kourafalou ${ }^{1,2}$ and K. Tsiaras ${ }^{1}$ \\ ${ }^{1}$ Hellenic Center for Marine Research, Anavyssos, Greece \\ ${ }^{2}$ Rosenstiel School of Marine and Atmospheric Science, Univ. of Miami, Miami, Fl, USA
}

Received: 3 April 2006 - Published in Ocean Sci. Discuss.: 30 May 2006

Revised: 6 October 2006 - Accepted: 15 December 2006 - Published: 24 January 2007

\begin{abstract}
A multi-nested approach has been employed for numerical simulations in the northern part of the Aegean Sea in the framework of the MFSTEP (Mediterranean Forecast System: Toward Environmental Predictions) project. The high resolution $(\sim 1.6 \mathrm{~km})$ hydrodynamic model of the North Aegean Sea (NAS) has been nested within a coarser model of the Eastern Mediterranean (resolution $\sim 3.6 \mathrm{~km}$ ) which is also nested within a basin scale model for the Mediterranean Sea (resolution of $\sim 7 \mathrm{~km}$ ). The high resolution of the NAS model allows the representation of topographic details that have never been reproduced in modelling studies of the region. Such details can enhance the simulation of coastal features, but can also influence basin-scale processes, such as the pathways of waters of Black Sea origin inflowing at the Dardanelles Straits and bifurcating through island passages.
\end{abstract}

We employ comparisons of the North Aegean and Eastern Mediterranean models in terms of computed flow fields and distribution of hydrodynamic properties, to evaluate the nesting procedure, the initialization requirements and the ability of a nested model to perform reliable short term simulations that employ high resolution atmospheric forcing, when initialized from a coarser OGCM.

We show that the topographic details of the high resolution, nested NAS model affect the distribution of the Dardanelles plume and the evolution of coastal currents, while the imposed high frequency, high resolution atmospheric forcing allows for the formation of an overall energetic flow field after a few days of spin-up period. Increased resolution and smaller coastal depth in the NAS simulations influence the flow through island passages and straits. A longer initialization procedure results in the establishment of stronger currents and better-developed buoyant plumes.

Correspondence to: V. Kourafalou

\section{Introduction}

The physical setting of the North Aegean Sea is unique, mainly due to the complex topography of islands, straits, peninsulas and a combination of very shallow and very deep regions. The North Aegean Trough consists of an extended deep area that forms around three major depressions (maximum depth near $1300 \mathrm{~m}$ ): the Sporades basin, the Athos basin and the Lemnos basin (Fig. 1). The deep basins separate shelf areas of the Northern Aegean from the generally deeper central basin interior. Examples are the shelf areas to the east and west of the Chalkidiki peninsula, where a number of rivers contribute to the development of coastal currents, which are also triggered by wind forcing. Larger than all the North Aegean rivers combined, is the buoyant inflow of waters of Black Sea origin through the Dardanelles Strait. The development and evolution of the Dardanelles plume is influenced by the presence of neighboring islands and the shallow Lemnos plateau, between the Lemnos and Imroz islands. Other topographic depressions include the Skyros basin and a small area south of the Lesvos island.

It is deduced that both the mean flow and the eddy field in the North Aegean Sea will be greatly influenced by the complicated topography, with implications on water mass characteristics and sub-basin exchanges. This is in addition to interactions with the Southern Aegean and with remote and local atmospheric forcing, see Poulos at al. (1997) and Zervakis et al. (2000). Several previous studies have focused on subbasin observations, mainly addressing seasonal variability, as Balopoulos et al. (1986), Zervakis and Georgopoulos (2002), Kontoyiannis et al. (2003) and Karageorgis et al. (2003). Studies focusing on North Aegean processes associated with the inflow of buoyant waters of Black Sea origin through the Dardanelles Strait include Zodiatis and Balopoulos (1993), Zodiatis (1994), Zodiatis et al. (1996) and Kourafalou and Barbopoulos (2003). 

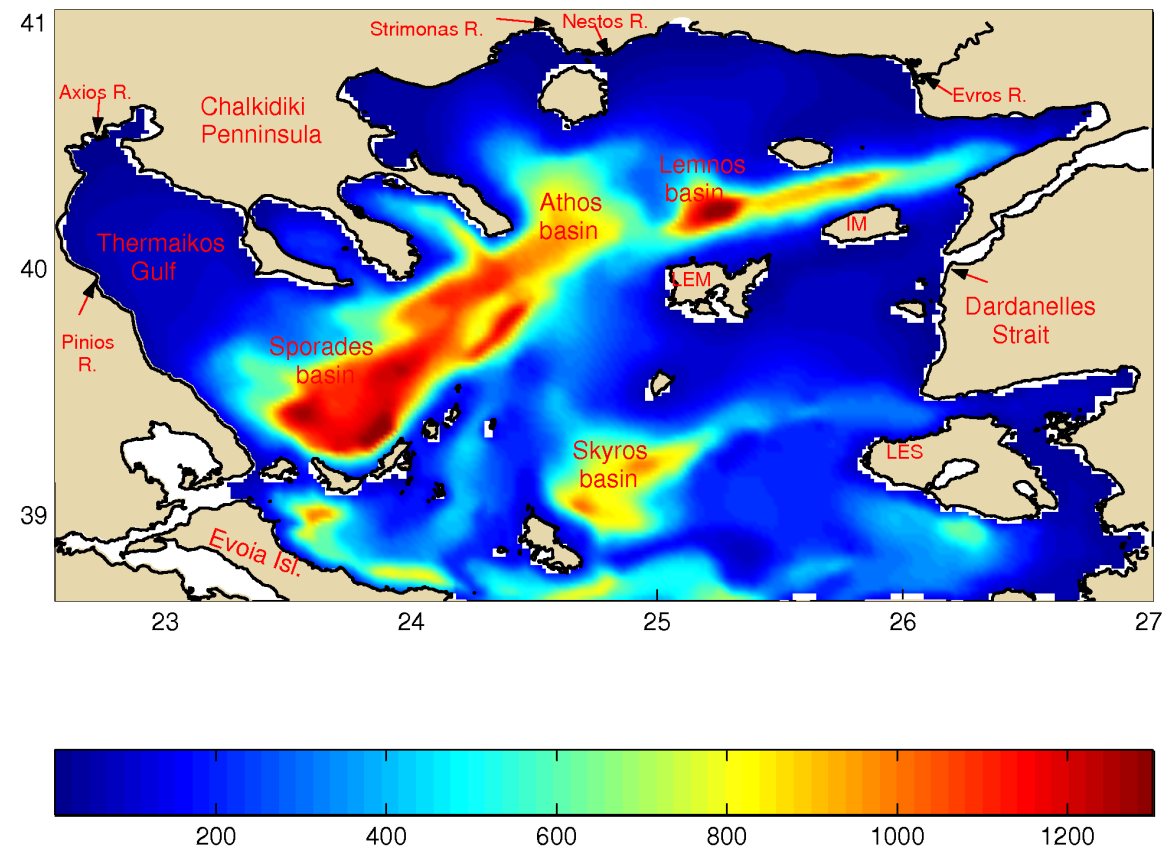

Fig. 1. The bathymetry of the North Aegean Sea (NAS) model, sub-basins and rivers. LES: Lesvos island; LEM: Lemnos island; IM: Imroz island.

This study is an extension of the model development and numerical simulations of the North Aegean circulation that took place during the Mediterranean Forecast System Pilot Project (MFSPP; Pinardi et al., 2003). The North Aegean model that was developed in the framework of MFSPP (Kourafalou and Barbopoulos, 2003) had a horizontal resolution of $\sim 3 \mathrm{~km}$ and was nested within the Aegean and Levantine Eddy Resolving Model (ALERMO) of a resolution of $\sim 5.5 \mathrm{~km}$ (Korres and Lascaratos, 2003) that was also nested in a basin-wide Mediterranean OGCM of $\sim 10 \mathrm{~km}$ resolution (Demirov and Pinardi, 2002). In MFSTEP, the same downscaling approach was employed in several areas of the Mediterranean Sea, including the Northern Aegean. The new North Aegean model domain remained the same (north of $\sim 38.5^{\circ} \mathrm{N}$, see Fig. 1), but horizontal resolution was doubled $(\sim 1.6 \mathrm{~km})$, following grid spacing decreases in ALERMO $(\sim 3.6 \mathrm{~km})$ and the Mediterranean OGCM $(\sim 7 \mathrm{~km})$. The scope of the North Aegean model simulations during MFSPP was the study of the seasonal variability; consequently, climatological atmospheric forcing was employed. The focus of the present study is on short term simulations with high frequency, high resolution atmospheric forcing that are initialized as a double nest on a longer running OGCM. The objective is to develop a nesting procedure that is suitable for the North Aegean, evaluate the initialization method and examine the effects of higher resolution on the simulated circulation fields.

The study motivation is linked to the longer term goal of pre-operational simulations with the North Aegean Sea
(NAS) model. We recognize that prior to attempting ocean forecasts, a series of experiments are necessary to avoid errors associated with the numerical procedure. In this context, we follow certain aspects of the methodology introduced by Atlas (1997) for the so-called OSSE's (Observing System Simulation Experiments), which employ nested numerical simulations to evaluate observational needs for forecast improvements. We consider the larger-scale ALERMO model (nested in the longer running OGCM) as our "nature run", giving an adequate representation of the basic circulation features that govern the Northern Aegean circulation. Our task is then to examine if the nested NAS model can successfully reproduce the features present in the outer model during short-term simulations. Complimentary tasks involve how the initialization procedure and differences in model set-up (such as resolution and topography) might modify the larger scale fields and possibly introduce additional circulation features, not present in the outer model. Our current experiments are only the first steps toward OSSE type simulations that will help design an integrated system of observations and data assimilative forecasts in the North Aegean.

\section{Model description}

\subsection{Model set-up}

The hydrodynamic model implemented in the Northern Aegean is based on the Princeton Ocean Model 
(POM, Blumberg and Mellor, 1983) which is a threedimensional, sigma-coordinate, free surface and primitive equation model. POM is a widely spread community model that has been used in numerous basin-scale, regional and coastal applications (details at http://www.aos.princeton.edu/ WWWPUBLIC/htdocs.pom/). The vertical eddy viscosity / diffusivity coefficients are evaluated according to the MellorYamada 2.5 turbulence closure scheme (Mellor and Yamada, 1982) while the calculation of horizontal diffusion is based on Smagorinsky (1963). The model domain (Fig. 1) lies between $22.53^{\circ} \mathrm{E}$ and $27^{\circ} \mathrm{E}$ and between $38.63^{\circ}$ and $41.03^{\circ} \mathrm{N}$. Horizontal resolution is approximately $1 / 60^{\circ}(\mathrm{DX} \sim 1.4 \mathrm{~km}$, DY $\sim 1.8 \mathrm{~km}$ ) while up to 25 sigma-levels are resolved in the vertical, with logarithmic distribution approaching the surface. The U.S Navy Digital Bathymetric Data Base (DBDB1, $1 / 60^{\circ} \times 1 / 60^{\circ}$ ) is used to build the model bathymetry with bilinear interpolation into the model grid; this is the best available bathymetry that covers the model domain. The minimum coastal depth (Hmin) is set at $10 \mathrm{~m}$; this is almost a third of the ALERMO Hmin of $26 \mathrm{~m}$.

Particular care has been given to the parameterization of riverine and Black Sea inputs. River inflows are modelled as source terms in the continuity equation, based on the plume dynamics study of Kourafalou et al. (1996). This parameterization allows for the development of buoyancy driven circulation that is mainly controlled by the amount of discharge and the interaction with wind stress and topography. All major North Aegean rivers (Evros, Axios, Aliakmonas, Pinios, Strimonas and Nestos) are represented (as 2-6 point sources) in the model. River runoff is set to constant values (same as in Kourafalou and Barbopoulos, 2003), based on climatological annual means (Therianos, 1974); higher frequency discharge values were not available. The Thermaikos Gulf (Fig. 1) river discharges have been modified as seasonal means according to measurements obtained during the METRO-MED project (Kourafalou et al., 2004). The fresh water is assumed of having zero salinity and seasonally varying temperature (the value for January is $10.5^{\circ} \mathrm{C}$ ). A parameterization different than the imposed net inflow in Kourafalou and Barbopoulos (2003) was adopted for the Dardanelles water exchange regime. The new scheme employs inflow of Black Sea Water (BSW) and outflow of Aegean water i.e., a two layer (inflow-outflow) open boundary condition with prescribed transport rates and BSW salinity (Nittis et al., 2006). In the present study the inflow and outflow transport rates follow a seasonal cycle with maximum values during July (Fig. 2) while BSW salinity is assumed constant (28.3 psu). The depth of the upper layer is assumed to be half of the total water column depth $(\sim 25 \mathrm{~m})$. A uniform velocity is calculated for the two layers according to the prescribed inflow/outflow transports. The same scheme was adopted by the ALERMO model.

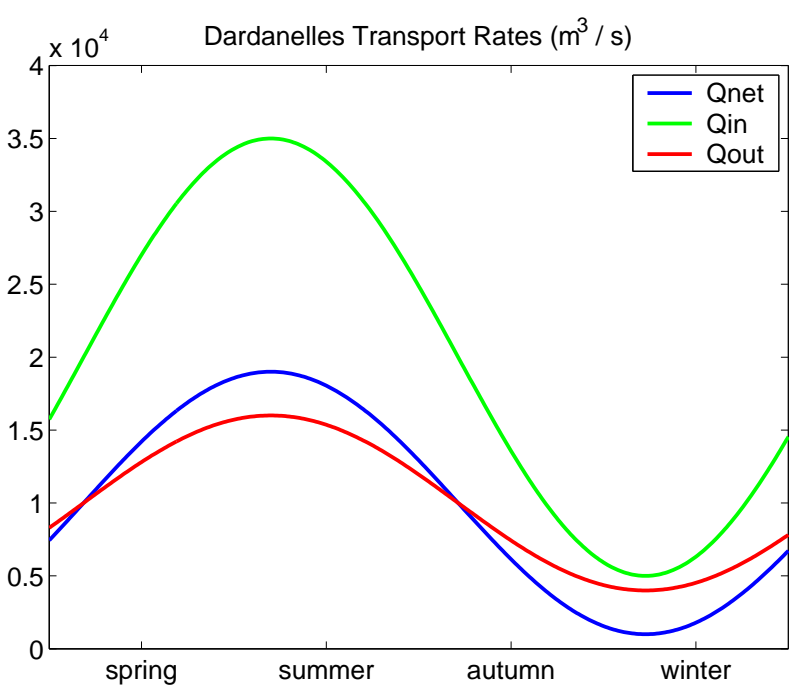

Fig. 2. The annual distribution of Dardanelles inflow ( $\left.Q_{\text {in }}\right)$, outflow ( $\left.Q_{\text {out }}\right)$ and net flux $\left(Q_{\text {net }}\right)$, as prescribed for the NAS and ALERMO models.

\subsection{Nesting procedure}

The Northern Aegean Sea (NAS) model has an open boundary to the south where it is nested to the coarser $\left(1 / 30^{\circ}\right.$ by $\left.1 / 30^{\circ}\right)$ intermediate model (MFSTEP-ALERMO, based on the POM code, http://www.oc.phys.uoa.gr/mfstep/ ALERMO_MFSTEP_DETAILS.htm, Sofianos et al., 2006). The intermediate model is at its turn nested to the Mediterranean-wide MFSTEP-OGCM model (http://www. bo.ingv.it $/ \mathrm{mfstep} /, 1 / 16^{\circ}$ by $1 / 16^{\circ}$ based on the OPA code, http://www.lodyc.jussieu.fr/opa/). The nesting-approach is one-way, i.e., each coarse model influences the solution within the immediate finer one, without any feedback.

The coupling procedure between the NAS and ALERMO models takes into account bathymetry fitting along the nesting boundary and employs the specification of flows and water properties. The NAS model grid and bathymetry along the open boundary are fitted to those of ALERMO in order to minimize interpolation errors for the open boundary input variables. The location of the nested boundary was carefully chosen to minimize bathymetric discrepancies between the two models (no islands or straits are present along the boundary). Daily average prognostic fields along the open boundary (total velocity $U, V$; barotropic velocity $U_{a}, V_{a}$, temperature $T$, salinity $S$, and surface elevation $\zeta$ ) are taken from the daily averaged ALERMO fields, which are bilinearly interpolated into the model grid and linearly interpolated in time providing lateral input of Velocity (total $U_{c}, V_{c}$ and barotropic $\left.U_{a c}, V_{a c}\right)$, Temperature $\left(T_{c}\right)$, Salinity $\left(S_{c}\right)$ and free-surface elevation $\left(\zeta_{c}\right)$ along the open boundary at each model time step. The following open boundary conditions are used: 

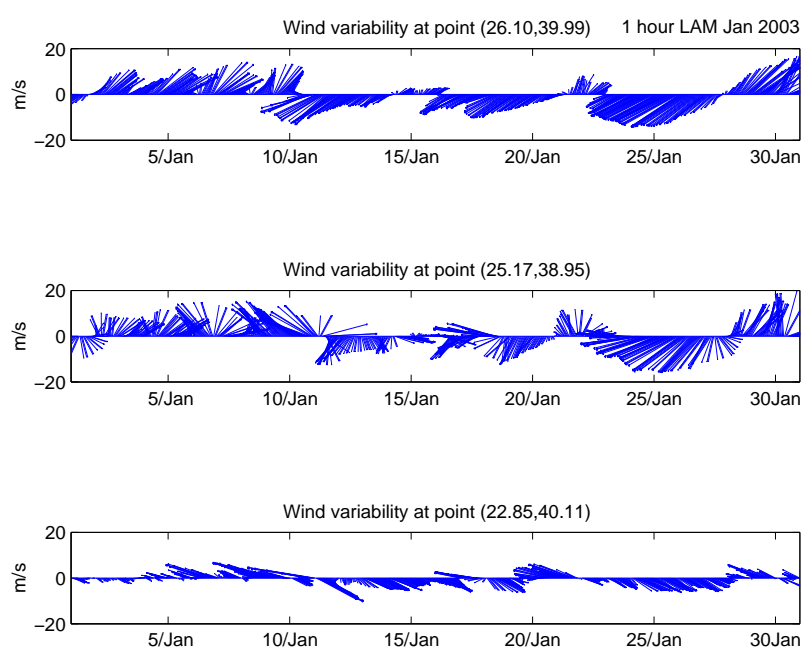

Fig. 3. Limited Area Model (LAM) atmospheric forcing time series for January 2003 at 3 points of the NAS domain; near the Dardanelles (upper); near the south NAS boundary (middle) and in the Thermaikos Gulf (bottom).

- An upstream advection scheme is used for $T, S$ when the normal velocity $V$ is directed outwards the model domain. When $V$ is directed inwards, $T$ and $S$ are directly prescribed by the ALERMO model.

$$
\begin{array}{ll}
\frac{\partial T, S}{\partial t}+V \frac{\partial T, S}{\partial y}=0 ; & V<0 \\
(T, S)=\left(T_{c}, S_{c}\right) ; & V>0
\end{array}
$$

- The baroclinic velocities are exactly prescribed by Alermo velocities:

$$
(U, V)=\left(U_{c}, V_{c}\right)
$$

- The free-surface elevation is not nested (zero-gradient boundary condition)

- The barotropic velocity normal to the south boundary is computed according to a Flather type radiation condition (Flather, 1976), while the tangential velocity is set equal to the Alermo velocity.

$\overline{V_{a}}=\bar{V}_{a c}-\sqrt{\frac{g}{H}}\left(\zeta-\zeta_{c}\right)$ and $\bar{U}_{a}=\bar{U}_{a c}$

where $g$ is the acceleration of gravity and $H$ the water column depth.

A volume constraint is applied on velocities normal to the open boundary to ensure that the water flux across the open boundary is the same with the one predicted by ALERMO.

\subsection{Initial conditions and forcing}

The model forcing employs 1-hour atmospheric forecast fields at $1 / 10^{\circ}$ resolution, that were provided by the SKIRON (http://forecast.uoa.gr/) atmospheric Limited Area Model (LAM) which is based on a non-hydrostatic version of the ETA/NCEP model (http://www.emc.ncep.noaa.gov/). The asynchronous air-sea coupling is based on a well-tuned set of bulk formulae for the computation of momentum, heat and freshwater fluxes, taking the following atmospheric parameters as input: wind velocity at $10 \mathrm{~m}$; relative humidity at $2 \mathrm{~m}$; air temperature at $2 \mathrm{~m}$; precipitation; net incoming short wave radiation; and incoming long wave radiation.

The net heat flux at the sea surface is given as the sum of radiative, sensible and evaporative components:

$Q=Q_{r}-Q_{e}-Q_{h}$

where $Q$ is the net heat flux to the ocean, $Q_{r}$ is the net radiative gain received by the ocean, $Q_{h}$ is the sensible heat flux and $Q_{e}$ is the evaporative heat flux.

The radiative term $Q_{r}$ in Eq. (1) consists of three components: the shortwave radiative gain received by the ocean $Q_{r s}$, the upward infrared radiation flux emitted by the ocean $Q_{i r u}$ and the downward atmospheric infrared radiation reaching the sea surface $Q_{i r d}$ :

$Q=Q_{r s}-Q_{i r u}+Q_{i r d}$

The net shortwave radiative gain at the sea surface $Q_{r s}$ is provided directly by the atmospheric model at 1 -hour intervals. The downward infrared radiation flux term $Q_{i r d}$ is also provided directly by the atmospheric model at 1 -hour intervals while the upward infrared radiation flux term is estimated by the ocean model itself using the Stefan-Boltzman law:

$Q_{i r u}=\varepsilon \cdot \sigma \cdot T_{s}^{4}$

where $\varepsilon$ is the ocean emissivity (as given by Bignami et al., 1995) and $\sigma$ is the Stefan-Boltzman constant respectively and $T_{s}$ is the sea surface temperature (predicted by the ocean model).

The evaporative $Q_{e}$ and sensible $Q_{h}$ heat flux terms are calculated by the ocean model using the bulk aerodynamic formulae (Rosati and Miyakoda, 1988; Castellari et al., 1998):

$Q_{e}=\rho_{\mathrm{A}} L_{V} C_{E}|\bar{W}|\left[e_{S A T}\left(T_{S}\right)-r e_{S A T}\left(T_{A}\right)\right] \frac{0.622}{p_{A}}$

$Q_{h}=\rho_{\mathrm{A}} c_{p} C_{H}|\bar{W}|\left(T_{S}-T_{A}\right)$

where the atmospheric data of wind speed $|\bar{W}|$ (at $10-\mathrm{m}$ above sea surface), air temperature $T_{A}$ and relative humidity $r$ (at 2-m above sea surface) are provided by the atmospheric model at 1-hour intervals. The atmospheric saturation vapour pressure $e_{S A T}$ in Eq. (8) is computed through a polynomial approximation as a function of temperature (Lowe, 1977). 


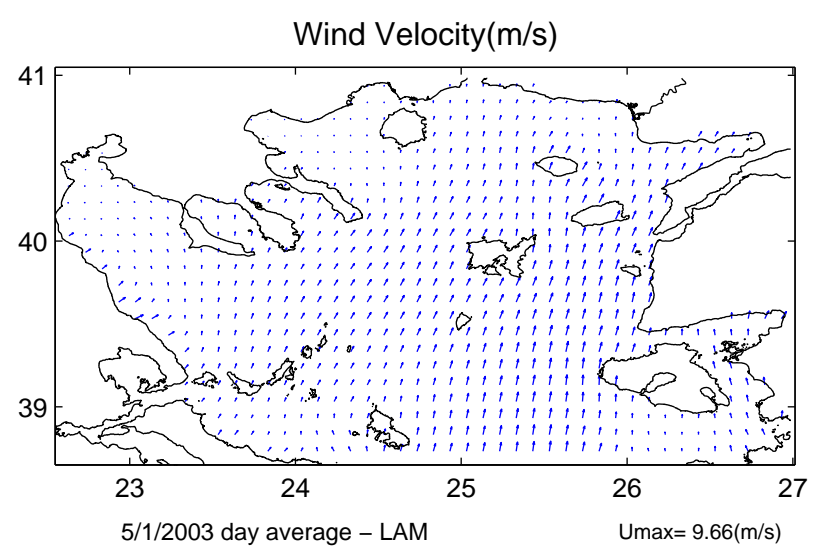

Wind Velocity $(\mathrm{m} / \mathrm{s})$

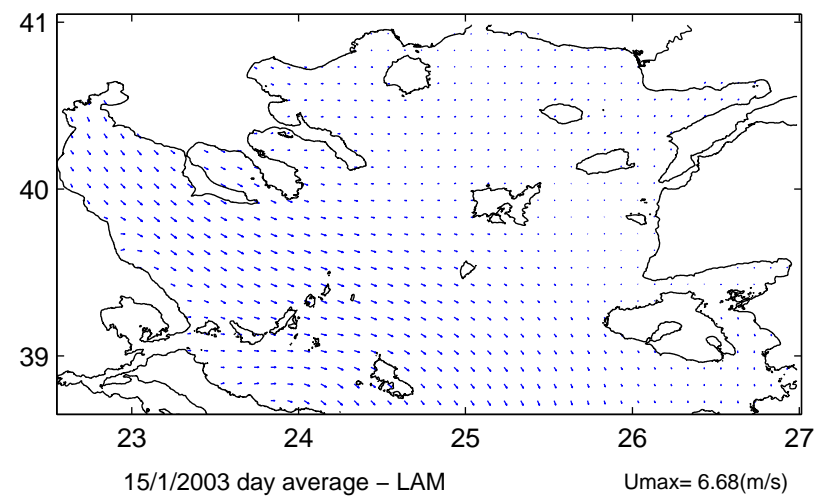

Wind Velocity $(\mathrm{m} / \mathrm{s})$

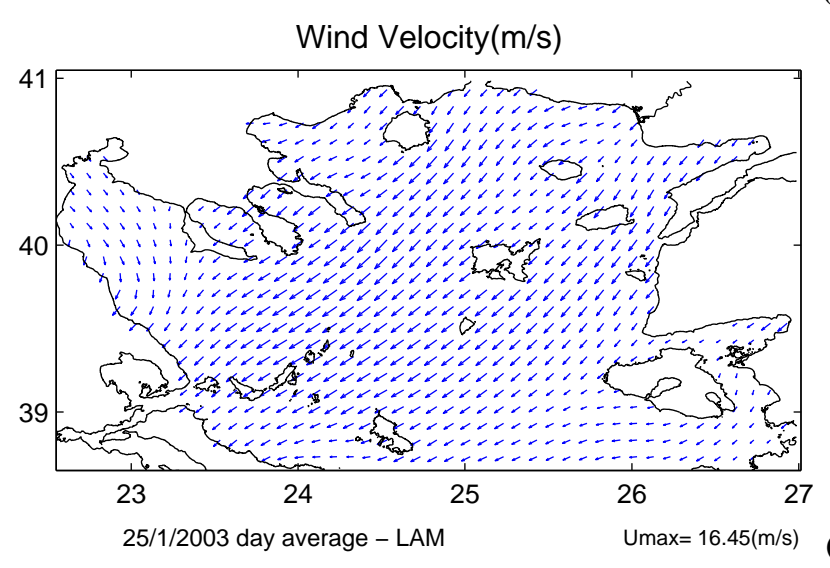

(c)

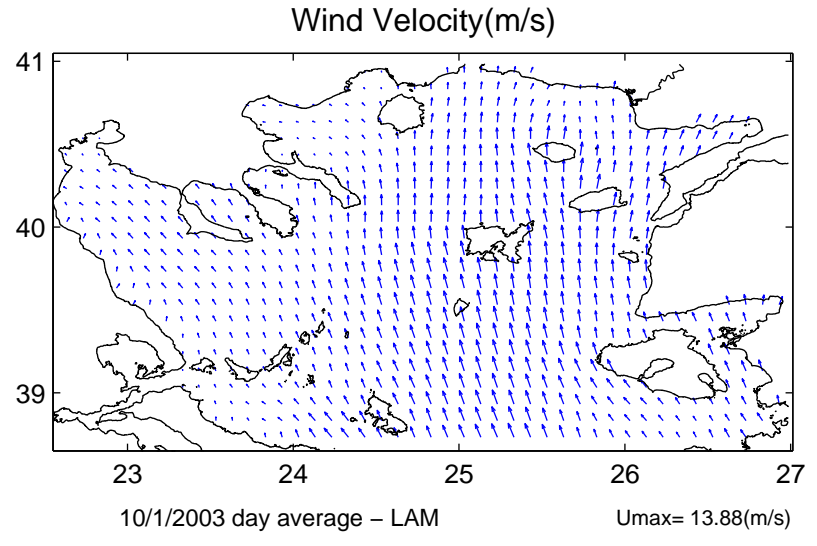

(a)

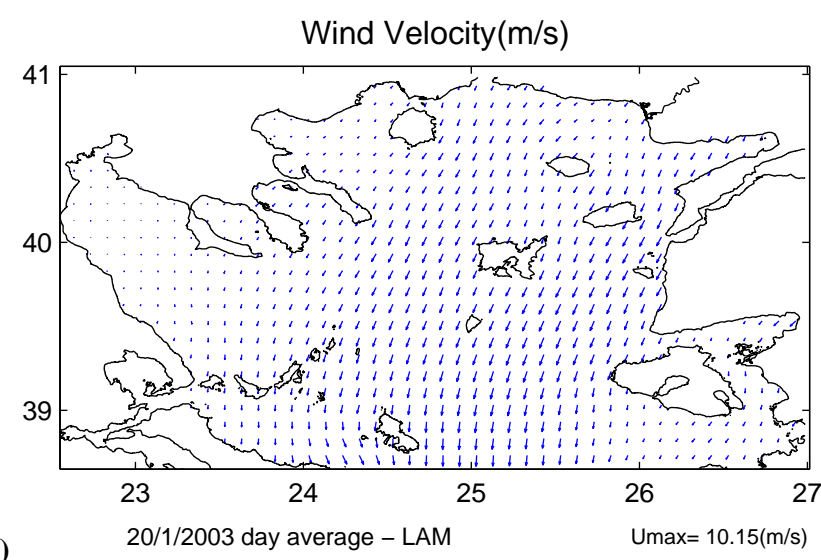

(d)

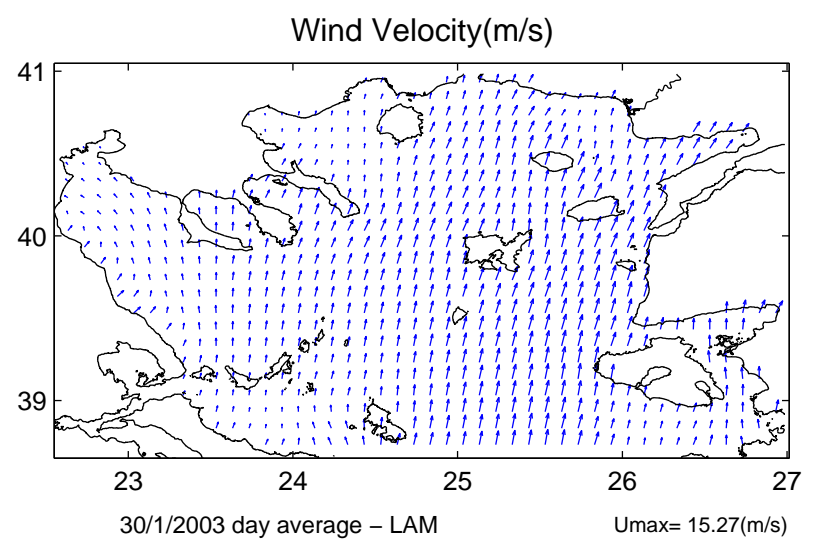

(f)

Fig. 4. Horizontal distribution of winds on January 2003 (5 day interval).

The specific heat capacity of air $c_{p}$ and the atmospheric pressure at sea level $p_{A}$ are considered as constants.

The sea surface temperature $T_{S}$ is predicted by the hydrodynamic model itself; the density of moist air $\rho_{A}$ is computed by the model as a function of air temperature and relative humidity; and the latent heat of vaporization $L_{V}$ is calculated as a function of sea surface temperature (Gill, 1982).

The turbulent exchange coefficients $C_{E}$ and $C_{H}$ are estimated in terms of air-sea temperature difference and the wind speed taking into account an atmospheric stability index based on the Kondo parameterisation (Kondo, 1975).

The virtual salt flux (VSF) surface boundary condition due to evaporation $E$ and precipitation $P$ are given by

$\mathrm{VSF}=(E-P) \cdot S$

where $S$ is the surface salinity predicted by the ocean model. Precipitation rates are provided by the atmospheric model at 
1-hour intervals while the evaporation rate is calculated from the evaporative heat flux using

$$
E=\frac{Q_{e}}{L_{V}}
$$

The calculation of the wind stress fields is based on the transformation of the 1-hour wind velocity data at $10 \mathrm{~m}$ above sea surface to $\mathrm{x}$ and $\mathrm{y}$ components of wind stress following the formula:

$\bar{\tau} \stackrel{\rho_{A}}{C_{D}}|\bar{W}| \vec{W}$

where $\rho_{A}$ is the density of moist air (computed by the ocean model as a function of air temperature and relative humidity), $W$ is the wind velocity and $C_{D}$ is the drag coefficient. The drag coefficient is calculated as a function of the wind speed and the air-sea temperature difference through the polynomial approximation given by Hellerman and Rosenstein (1983).

The initial conditions for Temperature, Salinity and Velocity as well as daily averaged fields along the open boundary were provided by the ALERMO model that was integrated for the same period (initialized from the basin-wide MFSTEP Mediterranean OGCM) using the same atmospheric input fields.

\section{Model simulations}

The model simulations described below are the first steps toward the establishment of a nested modelling system for the north Aegean that can achieve pre-operational capabilities. The purpose is to test if the NAS nested model that covers shelf and coastal areas can perform reliable short term simulations when initialized from the long running larger scale regional ALERMO model simulation that also provides the boundary conditions. In addition, high frequency and high resolution atmospheric forcing was employed to enhance circulation features. The limited amount of observational data available during the simulation period did not allow a detailed model validation, which was beyond the focus of the present study. No data assimilation techniques were employed, either. We focused on experiments that examined the nesting and initialization procedures and the ability of the nested model to spin up from rest and achieve circulation features present on the long-running larger scale model (with additional details due to the higher grid resolution) after a short (one month) period. The NAS shelf model simulated fields were compared to the ALERMO fields (which were taken as the closest to the "truth"), in order to test the nesting procedure, the air-sea coupling and the response of the higher resolution shelf model to the detailed atmospheric forcing.

The simulation period covered January 2003; the hourly LAM atmospheric forcing is illustrated in Figs. 3 and 4. Although the simulation period was short, the forcing was characterized by strong variability in the wind fields, both in time and space. As seen in Fig. 4, winds were strong, typical for the winter season, with the exception of the Northwestern basin of the Thermaikos Gulf, where they tend to be lighter (see also Fig. 3). The wind direction had an extended period of southerlies at the beginning, turning into periods of northeasterlies that alternated with brief calm periods; an episode of southwesterlies occurred toward the end.

We performed a series of sensitivity tests, using the ALERMO fields as our "truth", i.e. an adequate representation of the true state of our ocean system. We first attempted NAS runs that reproduce the basic oceanic features in ALERMO. We examined the impact of vertical resolution, boundary conditions and initial conditions. We evaluated effects of increasing the vertical resolution from 16 to 25 vertical layers and employing the ALERMO velocity $V_{\text {init }}$ in the calculation of initial fields (in addition to the $T$ and $S$ fields). We present the weekly averaged Sea Surface Height fields at the end of the integration period for three different simulations (Figs. 5a-c) and the corresponding ALERMO field (Fig. 5d). We also present the sea surface height difference between the two models in Fig. 6. In general, the nesting procedure performed well, as circulation patterns computed by ALERMO and by the NAS shelf model were compatible near the open boundary. Smaller scale features, developed in the shelf model, were absent in ALERMO, as expected, due to the higher shelf model resolution. We first focus on larger scale NAS features, which should appear more similar to the "true" ALERMO fields. Figures 5a and c show the results from two different initialization procedures. Starting from some discrepancies between the two models when vertical resolution was lower and no $V_{\text {init }}$ was included (Case I, Fig. 5a), we achieved better agreement by increasing the number of vertical layers from 16 to 25 (Case II, Fig. 5b). Features that are closer to ALERMO in the Case II simulation include a strengthened cyclone in the Sporades basin and the formation of an eddy south of the Lesvos island. The circulation in the deep basins of the shelf model (not shown) also acquires greater similarity to ALERMO, which we attribute to the improvement in the middle and lower level circulation, due to the higher vertical resolution. When the ALERMO velocity fields $V_{\text {init }}$ were not used (Figs. 5a, b), certain mesoscale features in the deeper basins along the North Aegean trough (Sporades and Athos basins) were not as well developed in the shelf model. This is attributed to the short integration time of the MFSTEP experiment that does not allow the full development of both the baroclinic and barotropic velocity fields; Zavatarelli et al. (2002) found that simulation of circulation in the Adriatic Sea with the Princeton Ocean Model required a 5-day spin-up time in diagnostic mode for the full development of the total velocity field, when initializing from the density field only. When the ALERMO velocity fields were used for initialization (Case III), the similarity to ALERMO improved, as is evident from the overall better agreement in the eddy field (Fig. 5c). This improvement is also evident from Fig. 6, where differences 

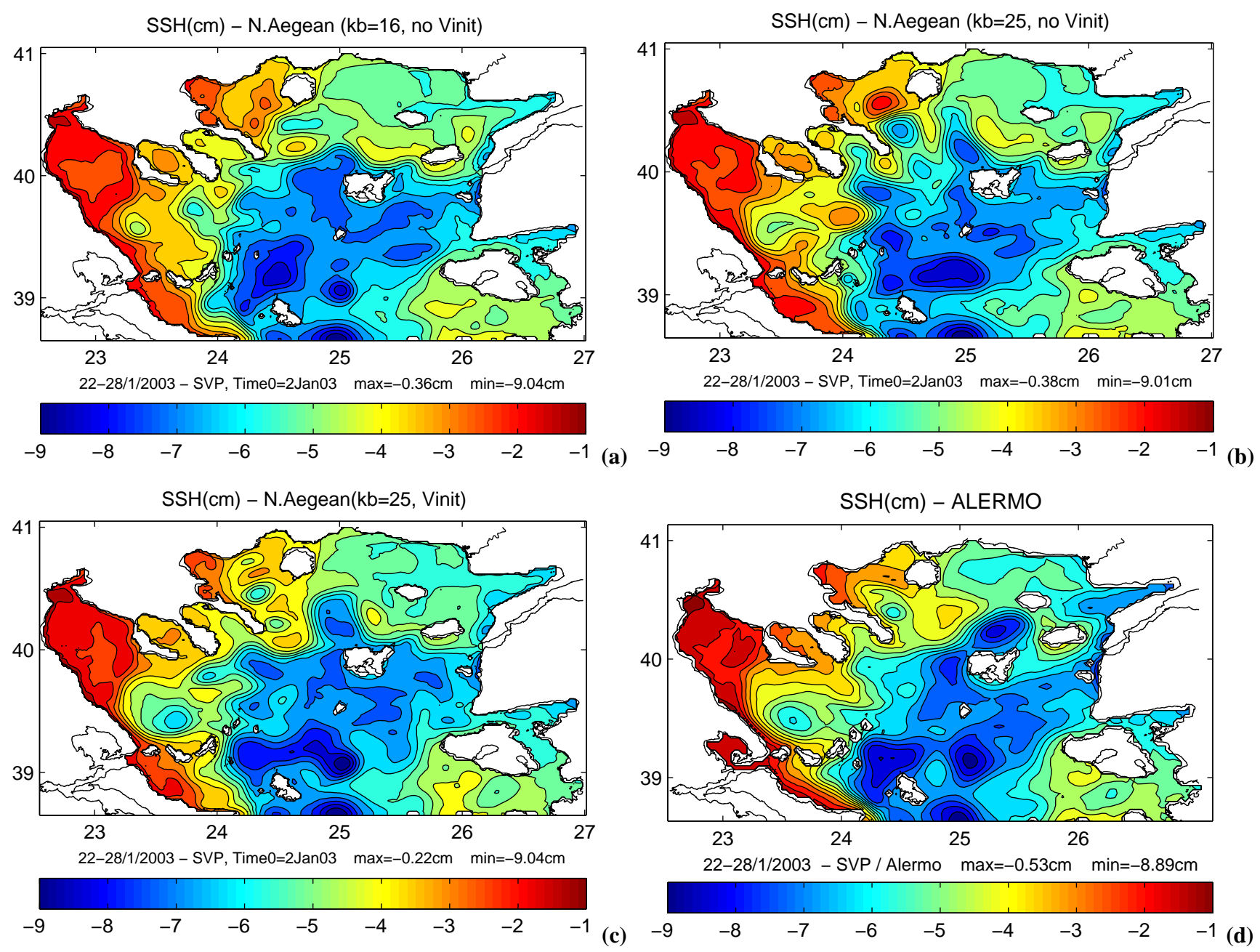

Fig. 5. Sea surface height weekly averaged for 22-28 January 2003 as simulated by (a) the N. Aegean model (kb=16, no Vinit); (b) the N. Aegean model (kb=25, no Vinit: NAS Case II); (c) the N. Aegean model (kb=25, Vinit: NAS Case III); (d) the ALERMO model.

were minimized in the Sporades basin and reduced in a number of other areas. However, disparities remained to the north and northeast of the Lemnos island, as this is the area mostly affected by the Dardanelles inflow where the salinity fields for the two models are most diverse, as we will discuss below.

The use of the ALERMO velocity fields for initialization increased the overall eddy kinetic energy in the shelf model. This is largely due to the strengthening of the deep shelf circulation, which is influenced not only by the density gradients, but also by the prevailing wind field and the local topography. Upper level features were also affected, as shown in Fig. 7 where the daily averaged velocity fields at $10 \mathrm{~m}$ are exhibited for the Case I, Case III and ALERMO simulations at the last day of integration (30 January 2003). The best qualitative agreement to ALERMO is for Case III, but both Case I and Case III exhibit overall more active eddy fields.
In Fig. 8 we compare the basin wide mean kinetic energy for the above experiments. In addition, we include one more ALERMO experiment that was continuous for 2002 and 2003 as a reference. Although the two ALERMO experiments were nested on different basin-wide Mediterranean models (Modular Ocean Model, MOM, for the longer simulations versus OPA for the January 2003 period), they both achieve the same mean kinetic energy time series during the common month, after an initialization period of about 6 days needed for the OPA nested simulation that started on the 1 January 2003. For the NAS experiments, it took a spin-up period of about 8 days for Case II and 5 days for Case III, but they both acquired higher mean kinetic energy during the period of persistent and rather weak northerlies until they merged with the ALERMO time series toward the end of the month, right after the maximum winds ( $\sim 25$ January) and the shift to the southerly direction. The higher mean kinetic energy in the NAS experiments is the cumulative result of 

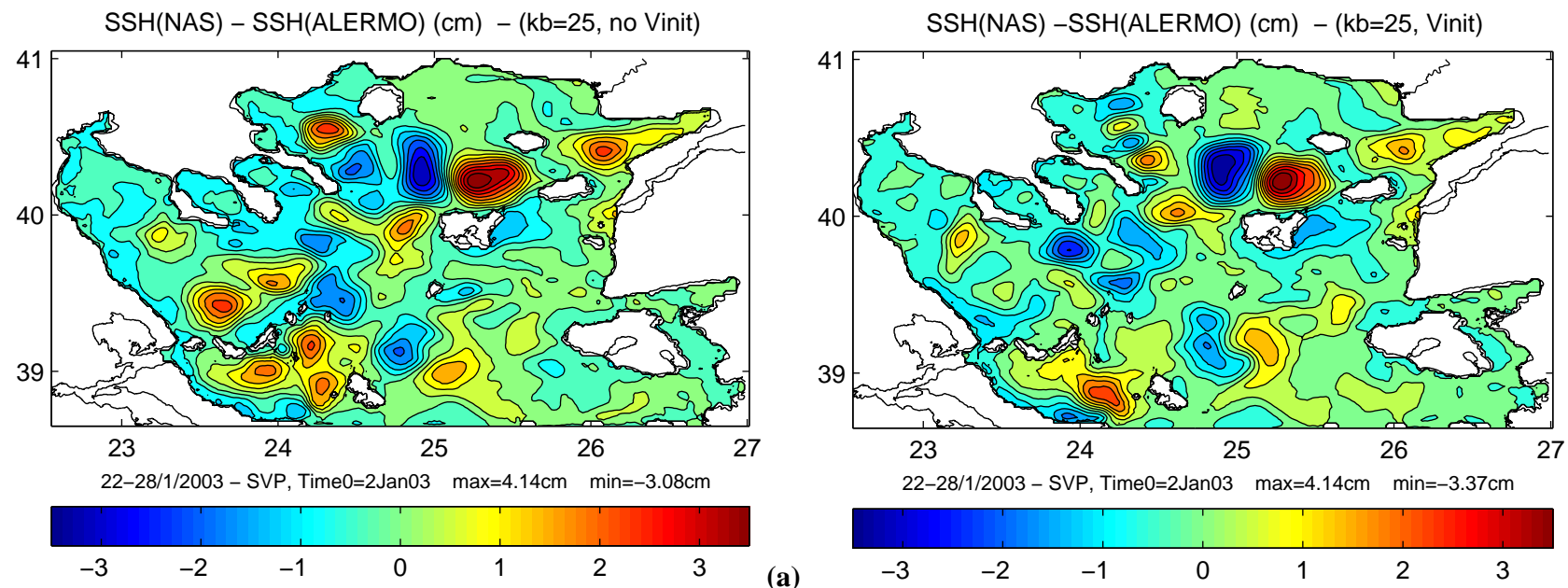

(b)

Fig. 6. Difference in the simulated sea surface height between the nested (a) NAS model case II (kb=25, no Vinit); (b) NAS model Case III $(\mathrm{kb}=25$, Vinit) and the outer ALERMO model: SSH(NAS)-SSH(ALERMO), averaged for 22-28 January.

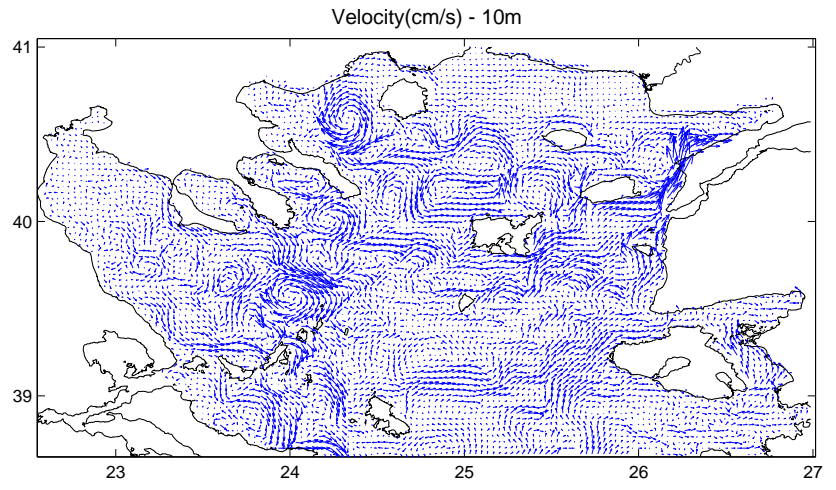

30/1/2003 - SVP

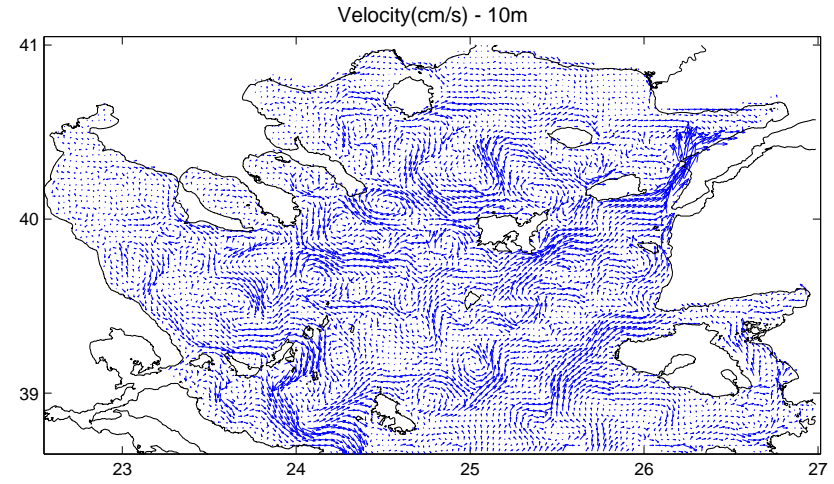

(a)
30/1/2003 - SVP

$\operatorname{Vmax}=101.14(\mathrm{~cm} / \mathrm{s})$ (b)

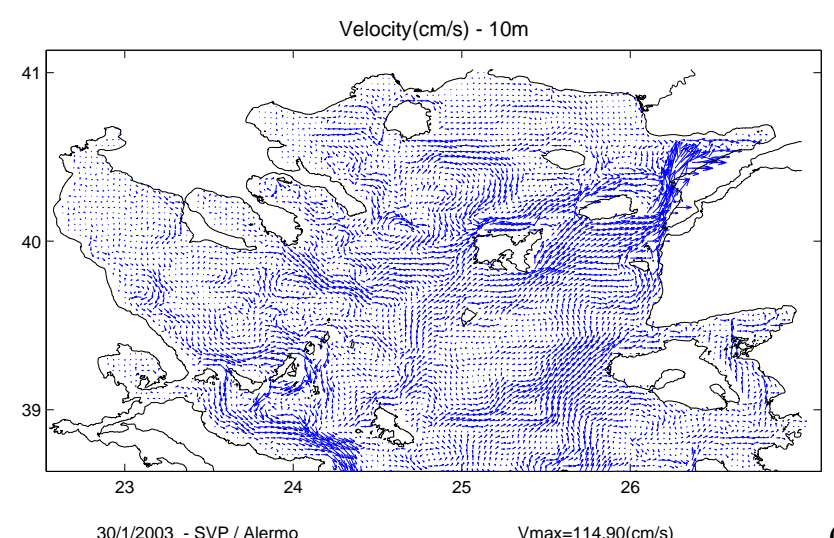

30/1/2003 - SVP / Alermo

$\operatorname{Vmax}=114.90(\mathrm{~cm} / \mathrm{s})$

(c)

Fig. 7. Velocity fields at 10m calculated from the (a) NAS Case II experiment, (b) the NAS Case III experiment and (c) the ALERMO, averaged over the last day of the simulation (30 January, 2003); the NAS fields are plotted every other vector to have the same number of arrows as in the ALERMO plot. 
several small eddies that are absent in the coarser ALERMO domain.

\section{Discussion of results}

We concentrate on the circulation patterns and the distribution of water properties as calculated in the Case III NAS experiments, which we will call the "base NAS run". We will employ the ALERMO results to identify differences in the computed fields between nested and outer models and understand what causes them. We will attempt a preliminary assessment of possible improvements in the simulations of the higher resolution NAS model versus the coarser ALERMO model. Limited observations were available during the simulation period and are used for model comparisons.

The NAS model simulated surface temperature patterns are quite similar to the ALERMO patterns. As seen in the weekly averaged distribution in Fig. 9, somewhat lower temperature values $\left(<0.8^{\circ} \mathrm{C}\right.$ difference $)$ are found in the coastal areas due to the lower NAS minimum coastal depth. As expected for winter, the temperature gradients are mainly North-South, rather than East-West as is common for summer (Kourafalou and Barbopoulos, 2003). The model values in the Thermaikos Gulf northern and western coastal areas (which are influenced by the cooler than ambient riverine waters) ranged from $10.5^{\circ} \mathrm{C}$ to $11.5^{\circ} \mathrm{C}$, while the interior Thermaikos temperatures reached $12^{\circ} \mathrm{C}$ to $12.5^{\circ} \mathrm{C}$; these values are consistent with in-situ measurements in other years (see Fig. 5 in Kontoyiannis et al., 2003).

A preliminary validation of model computed temperature in deep areas was attempted by employing the only available in-situ temperature data for the simulation period. As part of the POSEIDON system maintained by the Hellenic Center for Marine Research (Nittis et al., 2002; Nittis et al., 2006; http://www.poseidon.ncmr.gr/), buoy data were available offshore the Athos peninsula (Fig. 9). We note that this is a very difficult position for comparison to model results, as it is found within the seasonal frontal area that separates warmer waters of South Aegean and Levantine basin origin from the cooler North Aegean waters. However, a reasonable agreement between the NAS and buoy time series is observed in Fig. 10, with the exception of the warming event centered around the 9 January that can be attributed to a displacement of the frontal area. Interestingly, the NAS fields have an overall better agreement to the buoy data than the ALERMO fields. Further model validation with satellite derived (AVHRR) Sea Surface Temperature (weekly averaged SST maps of $1 / 8^{\circ}$ resolution, produced during MFSPP, Buongiorno Nardelli et al., 2003) although encouraging, was not conclusive, due to certain limitations in the satellite SST derived fields for this period.

Salinity patterns of the NAS model (Fig. 11) are quite similar to the ALERMO fields, but with somewhat more pronounced coastal features, due to the enhanced coastal cur-

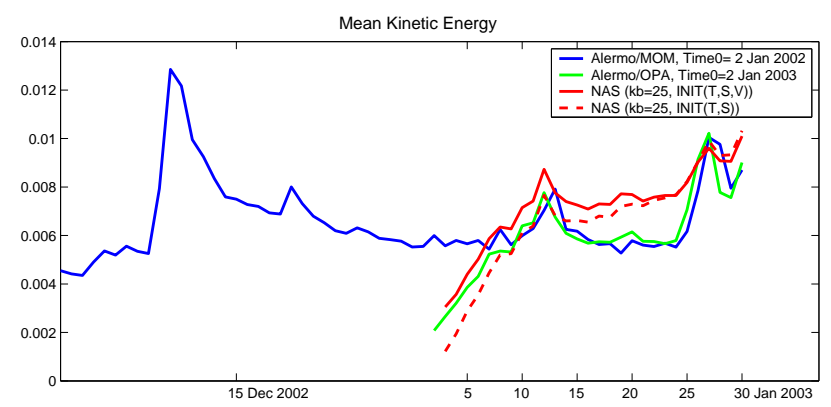

Fig. 8. Kinetic energy of the ALERMO (nested to the basin scale MOM model) Interannual simulation (blue line, start Time0=2/1/2002), the ALERMO (nested to the basin scale OPA model, start Time0=2/1/2003) January 2003 simulation (green line), the N. Aegean model with specified Vinit (red line; NAS Case III) and without (red dash line: NAS Case II).

rents. This is due to the lower coastal depths, the sharper slope near the coast (all factors influencing the wind-driven coastal current component) plus the inclusion of additional rivers (Evros, Pinios and Nestos that are absent in ALERMO, see Fig. 1), a factor that affects the buoyancy-driven component. The most pronounced changes were found in the pathways of the waters of Black Sea origin (BSW), which form the Dardanelles buoyant plume. Even though the parameterization of BSW inflow at the Dardanelles is the same, the inflow velocity field and consequently the simulated buoyant plume can vary, due to subtle topographic details, resulting from differences in resolution and minimum coastal depth.

We examine the effect of changes in the high frequency/high resolution wind field on the areas affected by buoyant discharges (mainly the Dardanelles plume area and the Northwestern shelf in the Gulf of Thermaikos). During the first 10 days, southerly winds dominate (Figs. 3, 4) which are downwelling-favourable for the east Aegean coast and greatly restrict the Dardanelles plume, but they are upwelling-favourable for the west coast and they allow offshore expansion of the low salinity band in the Thermaikos Gulf (not shown). The relaxation of the wind field in the middle of the month allows the release of low salinity waters in the vicinity of the Dardanelles and through the Lemnos plateau (Figs. 11a-b). The winds are almost negligible in the Gulf of Thermaikos, allowing the formation of a southward buoyancy-driven coastal current there that starts from the Axios River and continues to the south of the Pinios River. When the winds attain a strong northerly component everywhere (around the 25th, Fig. 11c), the Thermaikos coastal current is strengthened, as it is now both buoyancy and wind driven, while coastal currents are evident on other Northern Aegean shelf areas. The pool of low salinity waters that was advected on the Lemnos plateau gets quickly mixed with the ambient waters, while the core of the Dardanelles plume starts to retreat and is again found confined near the 

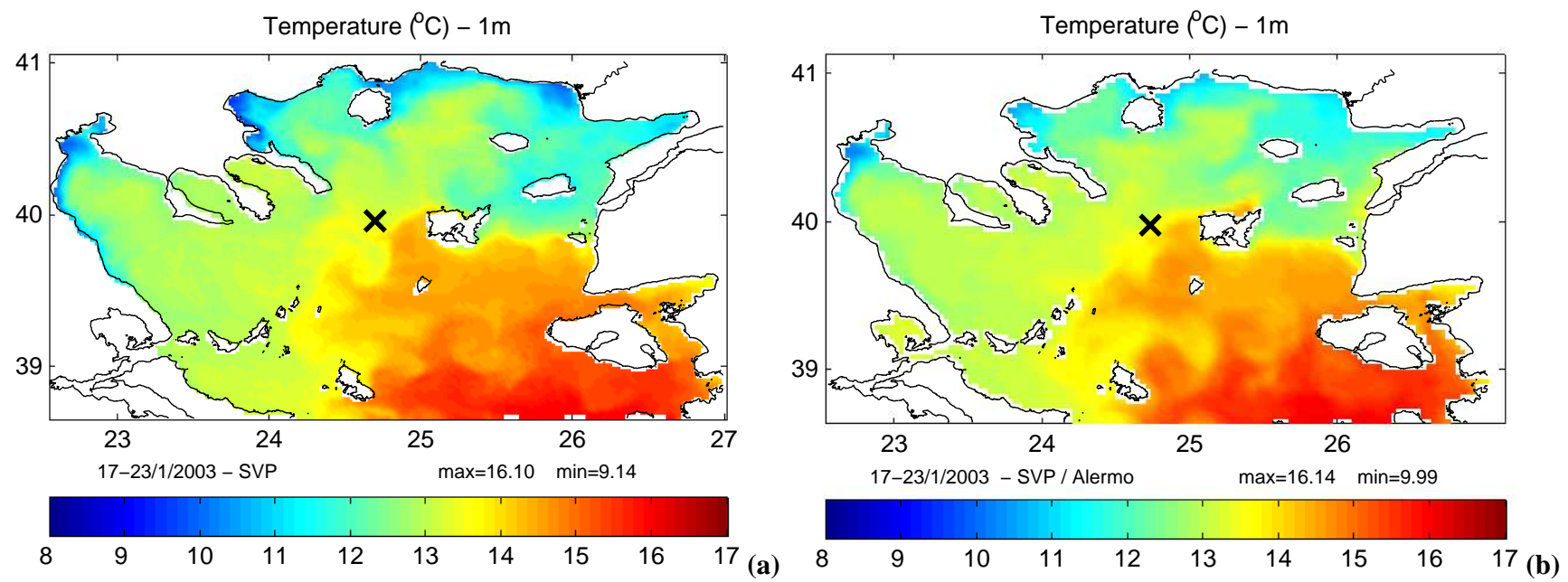

Fig. 9. Sea surface temperature weekly averaged for 17-23 January 2003 as simulated by (a) the N. Aegean model (NAS Case III) and (b) as simulated by the ALERMO model; the " $\mathrm{X}$ " marks the Athos buoy station.

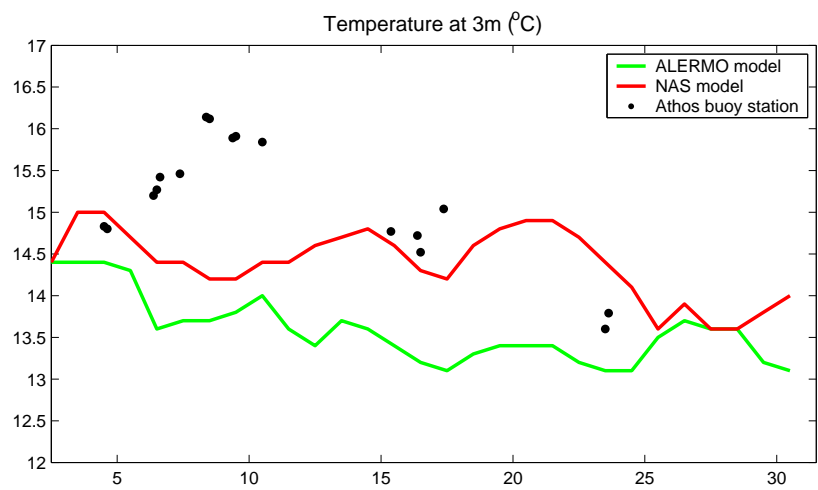

Fig. 10. Near-surface temperature time series of daily averaged values for the simulation period: ALERMO (green line); NAS Case III (red line); Athos buoy measurements (black dots); see Fig. 9 for buoy location.

Dardanelles Straits by the end of the month (30/1, Fig. 11d), when winds have shifted to southerlies. On the same day, an intrusion of higher salinity Aegean waters is evident in the Thermaikos Gulf.

We sought to examine certain details of the circulation computed by the NAS model in specific areas of the North Aegean Sea. We chose the Sporades basin (Fig. 1), where a strong eddy was present and flows exiting the basin were influenced by certain island passages and straits that are characteristic of the complexity in the NAS topography.

Both ALERMO and NAS simulations exhibited a strong cyclone in the Sporades basin, as exhibited from the SSH fields in Fig. 5. The so-called "Sporades eddy" is a known feature in this area, predominantly cyclonic in winter with occasional shifts to anticyclonic rotation in other seasons
(Kontoyiannis et al., 2002; Olson et al., 2007). We note that the NAS base run was designed to be the most representative NAS simulation of such large ALERMO eddy features. However, daily velocity fields reveal that the Sporades cyclone was more energetic in the NAS base run and filled with smaller circulation cells, as compared to the coarser ALERMO run. A near-surface velocity field comparison was made possible in this area, by employing Lagrangian measurements from a surface drifter in the Sporades basin. The instrument was part of a 2-year drifter campaign during 2002-2003 that is described in detail by Olson et al. (2007). We launched a simulated drifter in our NAS base run, starting with the position of the observed drifter on the 2 January 2003. The model simulated trajectory was calculated by a Lagrangian particle transport model which is based on Thorpe et al. (2004), using the daily averaged simulated velocity field at $10 \mathrm{~m}$ depth (same as the drifter drogue depth); no random walk was employed. The simulated and observed drifters are shown in Fig. 12a. Both patterns verify the presence of the Sporades cyclone during January 2003. The increased number of rotations performed by the instrument indicates that the eddy center was probably somewhat to the southeast from where the model predicted. This is not discouraging, as our model simulations have no correction to eddy positioning that is generally achieved through data assimilation. Furthermore, a complete agreement in trajectories is generally not expected, even among Lagrangian instruments that were launched in the same position, as circulation and chaotic behaviour near the initial drifter location have the potential to separate them. Examination of the model computed velocities at $10 \mathrm{~m}$ (not shown) revealed that the model drifter was launched at the periphery of the eddy and thus was quickly displaced northward. However, the model drifter still captured some smaller scale eddies, 

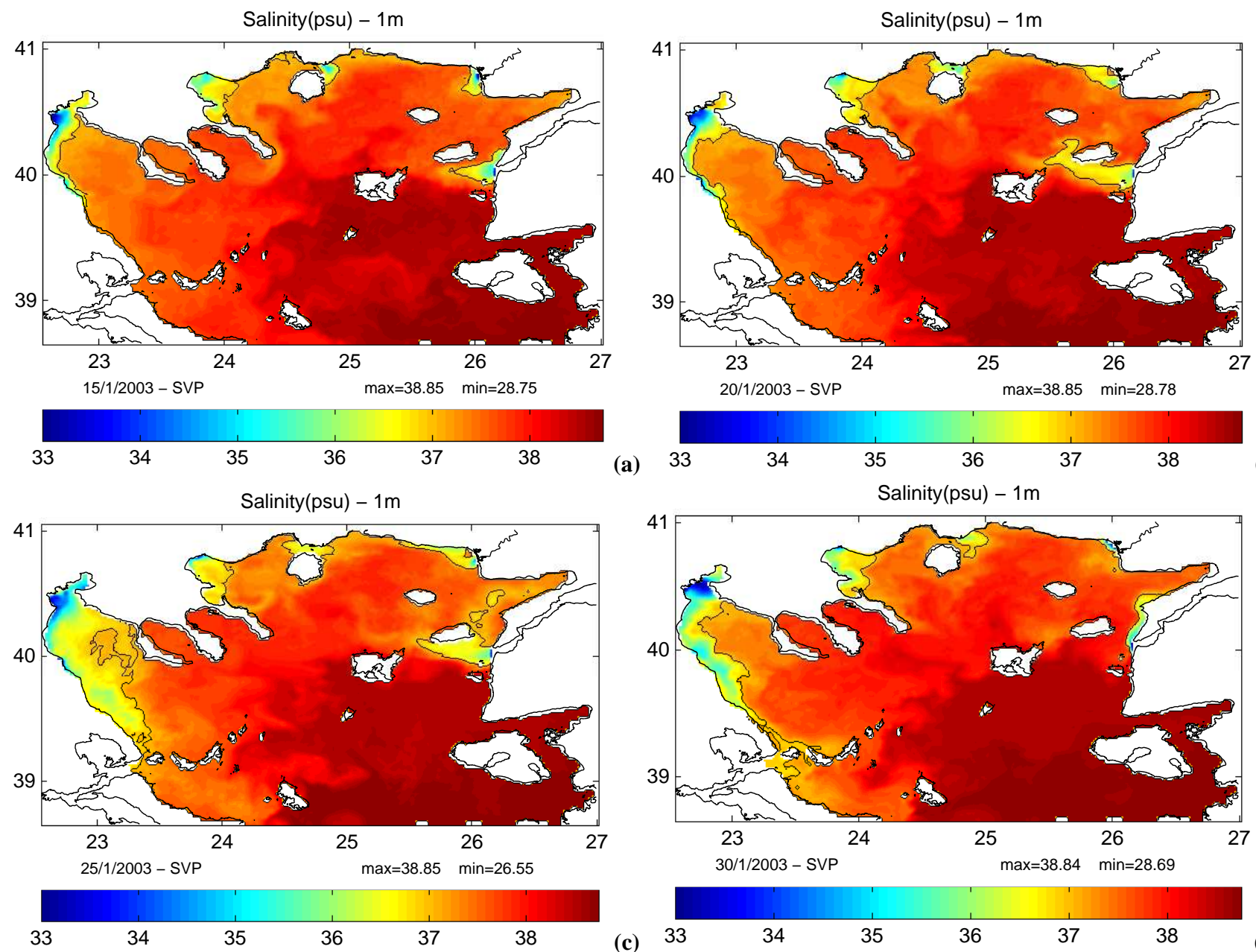

(b)

(c)

Fig. 11. Daily averaged, model simulated near surface salinity from the N. Aegean model (NAS Case III) on (a) 15/1/2003; (b) 20/1/2003; (c) $25 / 1 / 2003$ and (d) $30 / 1 / 2003$; the contour line marks the 37 isohaline.

similar to the observed trajectory. The instrument seemed influenced by a more energetic velocity field. Both model and observed trajectories were directed to the passage between the Skiathos and Skopelos islands; the observed drifter was stranded at the Skiathos coast. The average displacement speed was $11 \mathrm{~km} /$ day for the model, compared to $18 \mathrm{~km} /$ day for the data. The trajectory based on the ALERMO $10 \mathrm{~m}$ velocity field is shown in Fig. 12b. The prediction is inferior to the one from the NAS run, as no small scale eddies are indicated and the simulated drifter exit from the Sporades basin occurs further to the east, between the Skopelos and Alonissos islands.

We examine how the resolution of topography can influence the modelled flows. We performed a twin experiment to the NAS base run, where we employed the same coastal depth $H_{\min }$ as in ALERMO, i.e. $H_{\min }=26 \mathrm{~m}$ (as compared to $H_{\text {min }}=10 \mathrm{~m}$ for the base run). The model computed near surface velocity fields from the two NAS simulations and the corresponding ALERMO fields are shown as details of the full model field in Fig. 13 for the domain around the Sporades islands and in Fig. 14 for the domain around the Lemnos plateau. The velocities are daily averaged for 30/1/2003 (Fig. 13), when the prevailing winds were from the south and for 25/1/2003 (Fig. 14), when the prevailing winds were from the north.

As seen in Fig. 13, flows between the island passages are more similar in the two NAS runs, than with ALERMO. For instance, they allow flow through the Pelagonissi and Gioura islands, which is not possible in ALERMO, due to the coarser resolution. This has an influence on the predicted salinity fields (Fig. 11d), as the low salinity band along the western Thermaikos is detached from the coast due to the upwelling-favorable winds, impacting the exiting flow pathway from the North to the South Aegean. The two NAS runs also allow a wind-driven northward flow in the passage between Skiathos and the Pilion peninsula, which is absent in 

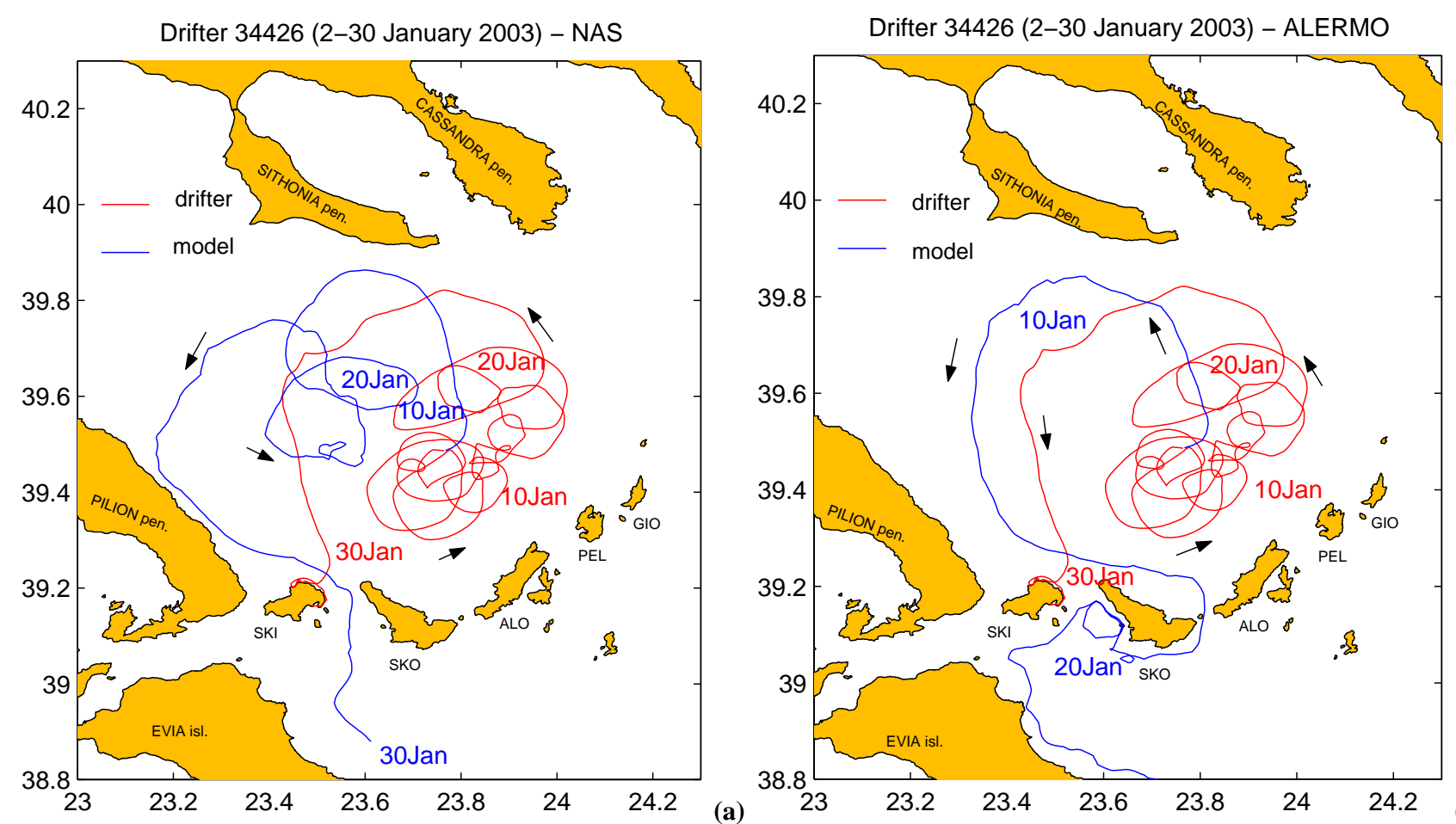

(b)

Fig. 12. (a) NAS Case III results; (b): ALERMO results. Comparison of model predicted (blue line) and observed (red line) trajectories at $10 \mathrm{~m}$, which is the observed drifter drogue depth. The drifters followed a cyclonic eddy in the Sporades basin, to the north of the Sporades island arc. The 5 main Sporades islands are marked in the left panel: SKI (Skiathos); SKO (Skopelos): ALO (Alonissos); PEL (Pelagonissi, also called Kyra Panagia); GIO (Gioura).

ALERMO. This northward flow continues as a coastal current along the eastern edge of the Pilion peninsula in the NAS runs only. Differences in the flow between the Skiathos and Skopelos islands are also evident. The ALERMO run resolves this passage only partially, due to coarser resolution, while a preferred pathway along the deeper part of the passage, near the Skopelos island, is obvious in the ALERMO and NAS runs with $H_{\min }=26 \mathrm{~m}$.

The Dardanelles inflow dominates the velocity fields in Fig. 14. The input is near the east part of the presented model detail. The low salinity waters from the Dardanelles follow a predominantly westward pathway, influenced by both buoyancy and the northerly wind stress, as was shown in the salinity field of Fig. 11c. The bifurcation of the Dardanelles induced flow around the Imroz island is obvious in all three model simulations, but the branch south of Imroz is more pronounced in ALERMO, which does not resolve a secondary flow around the Tenedos island. Both resolution and minimum coastal depth seem to play a role in directing the flow toward the eastern part of the passage between the Imroz and Lemnos islands in the ALERMO and NAS $H_{\min }=26 \mathrm{~m}$ runs. This has a pronounced effect on the downstream flow, which is strongly deflected away from the north coast of the Lemnos island, as compared to the NAS base run.
Consequently, an anticyclonic eddy is observed near the tip of the Athos peninsula in the NAS base run, which is moved further north in the NAS $H_{\min }=26 \mathrm{~m}$ run and is absent in the ALERMO run.

In order to examine how the choice of initial fields influenced the NAS computed fields for January 2003, we utilized ALERMO fields from the continuous 2002-2003 simulation depicted in Fig. 8, to initialize the NAS model on 2 September 2002. We then ran with the same (coarser) atmospheric fields until 2 January 2003, when we imposed the LAM fields as before. Consequently, the simulations during January 2003 were identical, with the exception of the initial fields. In the new simulation, we initialized from the temperature and salinity fields (no velocity) of 1/1/2003 from the simulation that started on $2 / 9 / 2002$. We observed that the NAS model was capable of establishing an overall enhanced current field (as compared to the Case I experiment, that did not have velocity in the initial condition), as the longer initialization period allowed the full development of circulation features. In addition, submesoscale eddies were also enhanced, as they were not suppressed by the imposition of the coarser ALERMO velocity fields. The river plumes and the Dardanelles plume also appeared more developed. This suggests that short term simulations of downscaled nested shelf 

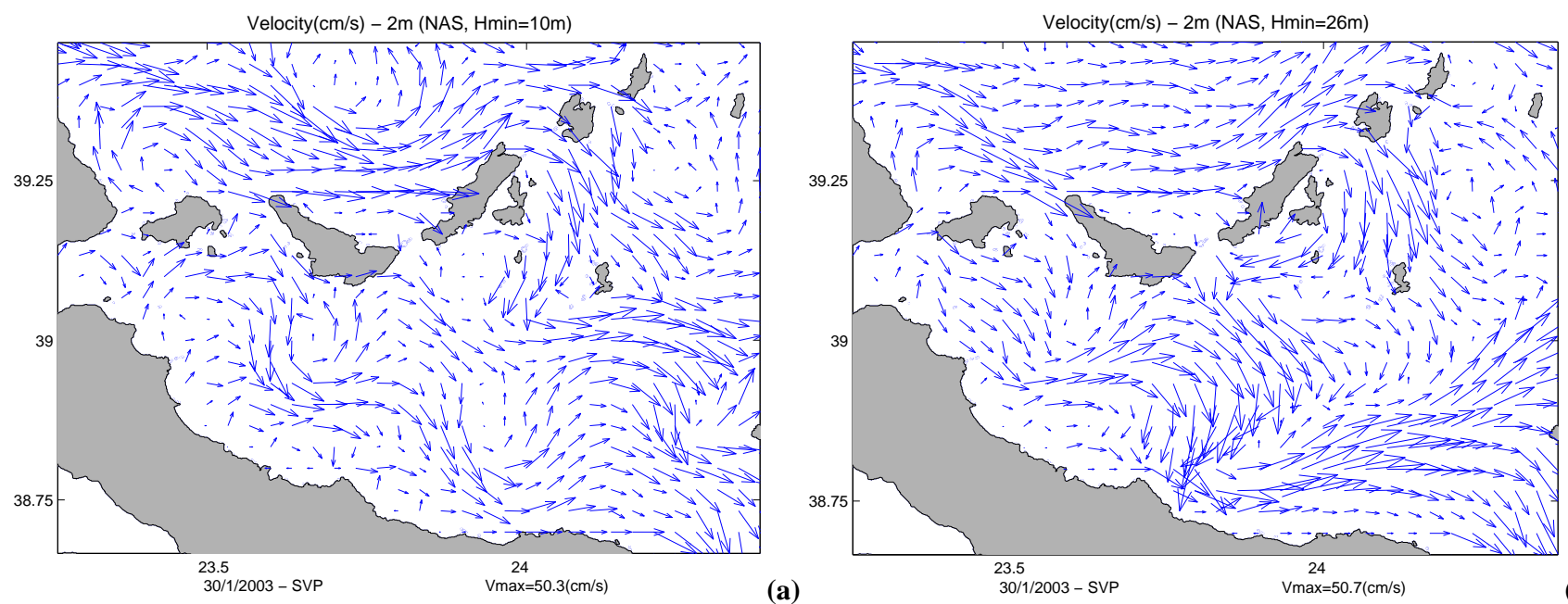

(a)

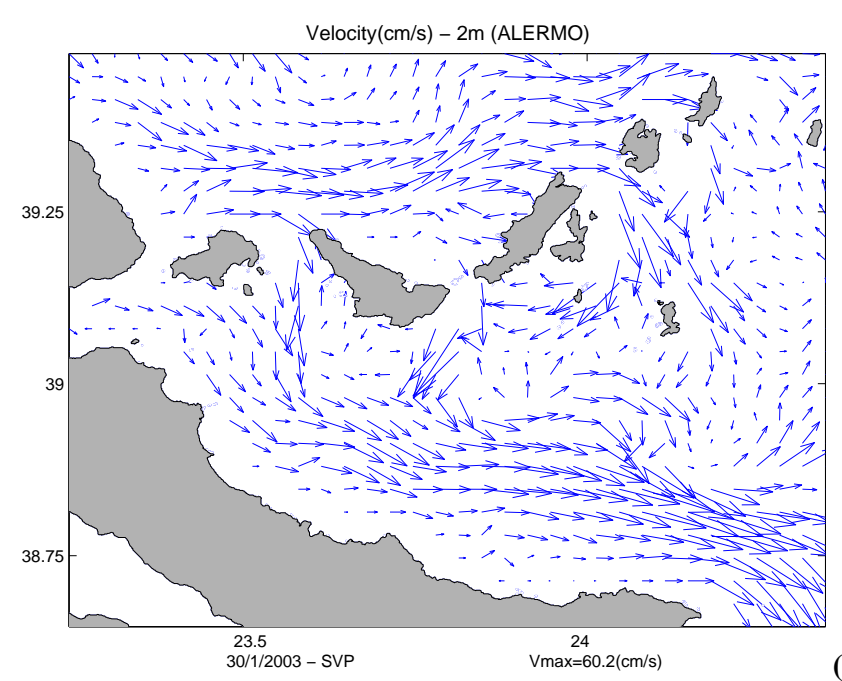

(b)

Fig. 13. Velocity at $2 \mathrm{~m}$ around the Sporades islands (see Fig. 12 for island names): (a) NAS Case III, $H_{\min }=10 \mathrm{~m}$; (b) NAS Case III, $H_{\min }=26 \mathrm{~m}$; (c) ALERMO, $H_{\min }=26 \mathrm{~m}$. Velocity fields are daily averaged for 30/1/2003; prevailing winds were from the south. The NAS fields are plotted every other vector to have the same number of arrows as in the ALERMO plot.

(NAS) and regional (ALERMO) models in areas of high variability as the Aegean Sea might not allow the full development of circulation features, a problem that does not appear to be overcome by employing high resolution atmospheric fields. This agrees with the findings of Natale et al. (2006) where short simulation periods of a high resolution nested model that were initialized by the coarser outer model did not allow the evolution of surface features that were developed due to the nested model's high resolution atmospheric forcing.

\section{Concluding remarks}

The modeling of the entire North Aegean in very fine resolution (averaging $1 \mathrm{~min}$ or $\sim 1.6 \mathrm{~km}$ ) and under atmospheric forcing that allows temporal and spatial details (1-hour forc- ing from an atmospheric Limited Area Model of 1/10 degree or $\sim 9.5 \mathrm{~km}$ resolution) has been performed for the first time, in the framework of the MFSTEP project.

The shelf and coastal areas in the North Aegean model domain exhibited a rapid response to the variability of the atmospheric forcing. The wind was a major circulation driving mechanism during January 2003, as is common for the winter season. The high frequency variability in the wind input resulted in rapidly shifting coastal currents and remarkable changes in the advection of low salinity waters within areas affected by the river plumes and around the Dardanelles plume. Despite the short integration period, forcing variability was substantial, as the wind field changed from strong southerlies in early January to strong northerlies in late January with a wind relaxation period in between and with a return to southerlies by the end of the month. Spatial vari- 

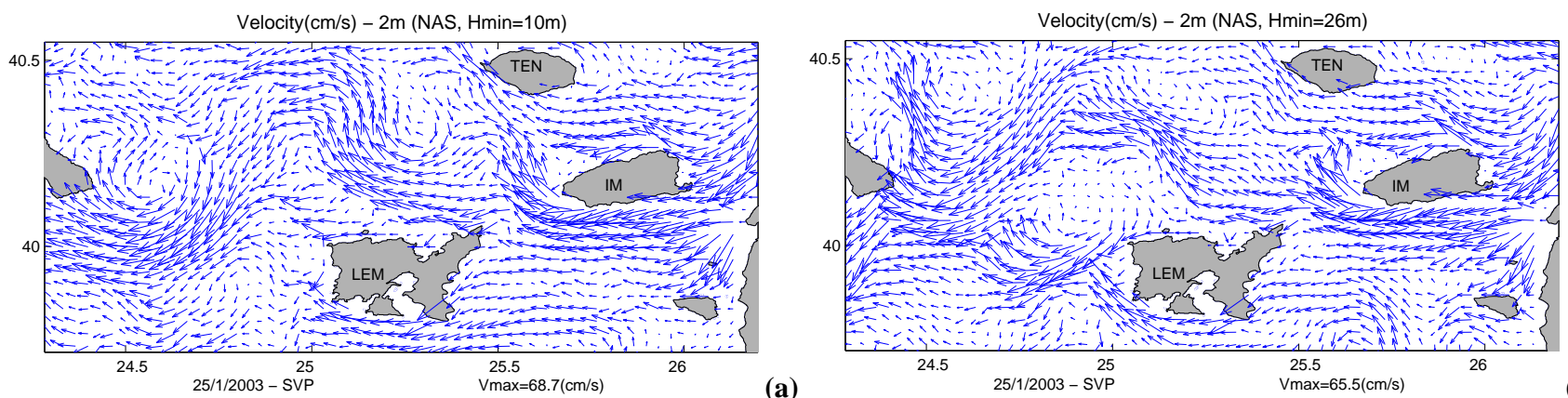

(b)

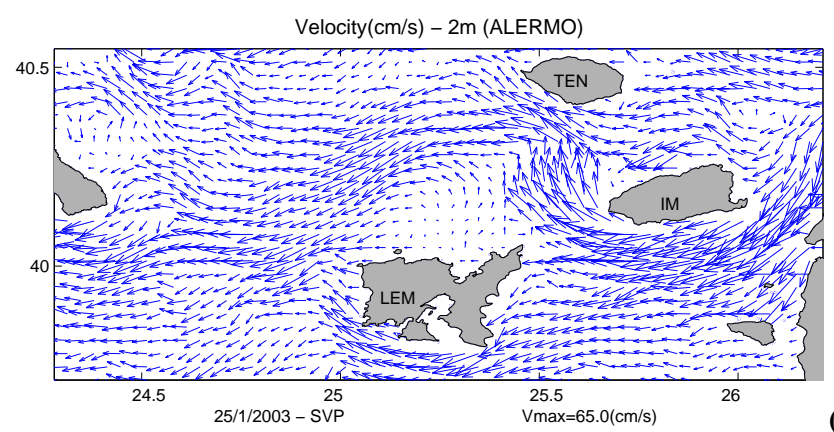

(c)

Fig. 14. Velocity at $2 \mathrm{~m}$ around the Lemnos basin (LEM: Lemnos island, IM: Imroz island; TEN: Tenedos island): (a) NAS Case III, $H_{\min }=10 \mathrm{~m}$; (b) NAS Case III, $H_{\min }=26 \mathrm{~m}$; (c) ALERMO, $H_{\min }=26 \mathrm{~m}$. Velocity fields are daily averaged for 25/1/2003; prevailing winds were from the northeast. The NAS fields are plotted every other vector to have the same number of arrows as in the ALERMO plot.

ability in the wind field was also observed, especially for the Gulf of Thermaikos area (Northwest Aegean shelf), where winds were weaker and generally different in their east-west component, as compared to the rest of the domain.

Comparison to the limited observations available during the simulation period offers cautious encouragement on model skill; simulations over periods that have better data coverage are necessary for model evaluation. A forecast system for the North Aegean will benefit from time series of measurements in island passages and straits. As a prelude to such a system, we focused on comparisons between the nested NAS model predictions to those of the outer ALERMO model that was perceived as adequately representing the major circulation features. We evaluated approaches in the nesting and initialization procedure to determine the preferred NAS basic run. The chosen Case III run has high vertical resolution and employs the velocities along with the $\mathrm{T}$ and $\mathrm{S}$ fields during the initialization procedure. We also examined the effects of higher resolution and more detailed topography on the predicted circulation patterns. We showed that coastal currents and flows through island passages and straits are influenced by both the higher resolution and the more detailed coastal topography present in the nested model. A comparison of basin-wide energetics showed that the nested model exhibited an overall increased eddy field.
The short period of the experiment is representative of future pre-operational simulations and forecasts. An interesting finding for the North Aegean, an area that incorporates both coastal and deep areas, is the need to employ the outer model velocity fields in the nesting procedure, rather than relying on the initial field, to allow the development of certain circulation features in the deep areas. This method was found to be equivalent with a longer spin-up period for the nested model which, however, is not practical in pre-operational simulations.

The two areas that are mostly influenced by buoyant discharges, namely the Gulf of Thermaikos and the Dardanelles plume (around the Lemnos island), were discussed in terms of salinity changes caused by the influence of wind on the surface advected plumes. We should caution that all North Aegean rivers and the Dardanelles inflow were "climatological" values, not necessarily representative of the January 2003 conditions, as no such information was available. However, we focused on the study of certain processes, especially the simulated rapid changes in coastal flows and river plumes, in response to the varying wind conditions. The coastal current along the western Thermaikos Gulf and the changes in width and alongshore extension due to wind effects has been previously documented in a study that combined observations and modelling to discuss the related processes and their seasonal variability (Kontoyiannis et al., 2003). Here, we showed that similar changes can be ex- 
pected in shorter time periods, due to episodic changes in wind forcing. Additional riverine sources and better resolution of shallow areas resulted in enhanced coastal currents in the NAS results, especially during northerly winds that enhanced buoyancy-driven currents due to river discharges. For the Dardanelles plume, the NAS and the ALERMO models exhibited the strongest differences in salinity and velocity patterns. This was attributed to differences in topographic details near the Dardanelles, which, although small, influenced the transport rates and pathways of the buoyant waters through the island passages; associated changes in downstream flows (such as the eddy field in the Athos basin) were also observed. This is an important finding, as details in the initial distribution of the Dardanelles plume may influence the pathways of this strongest lateral buoyant input for the North Aegean, with implications on the general circulation in the area and possibly influencing water properties in the entire Aegean Sea. The future development of a North Aegean model for forecast purposes requires details in river discharges and a parameterization of the Dardanelles flow exchange based on comprehensive direct measurements. In addition, data assimilation and model validation exercises are necessary steps and should be undertaken together with the development of a suitable observational framework, which is currently very limited.

Acknowledgements. The study was supported by the EU funded MFSTEP project (contract EVK3-CT-2002-00075). The drifter data were obtained from a study funded by the U.S. Office of Naval Research (ONR grants N000140110134 and N000140310439), in collaboration with Don Olson and Bill Johns of the University of Miami. We thank Jean Carpenter for graphics assistance. We appreciate the fruitful working relationship with all colleagues in the modeling group of the MFSTEP project.

Edited by: D. Webb

\section{References}

Atlas, R.: Atmospheric observations and experiments to assess their usefulness in data assimilation, Journal of the Meteorological Society of Japan, 75(1B), 111-130, 1997.

Balopoulos, E. T., Collins, M. B., and James, A. E.: Residual circulation in a coastal embayment of the Eastern Mediterranean Sea (Thermaikos Bay, N.W. Aegean), Thalassographica, 9, 722, 1986.

Bignami, F., Marullo, S., Santoleri, R., and Schiano, M. E.: Longwave radiation budget in the Mediterranean Sea, J. Geophys. Res., 100(C2), 2501-2514, 1995.

Blumberg, A. F. and Mellor, G. L.: Diagnostic and prognostic numerical circulation studies of the South Atlantic Bight, J. Geophys. Res., 88(C8), 4579-4592, 1983.

Castellari, S., Pinardi, N., and Leaman, K.: A model study of air-sea interactions in the Mediterranean Sea, J. Mar. Syst., 18, 89-114, 1998.
Demirov, E. and Pinardi, N.: Simulation of the Mediterranean Sea circulation from 1979 to 1993 . Part I: The interannual variability, J. Mar. Syst., 33/34, 23-50, 2002.

Flather, R. A.: A tidal model of the northwest European continental shelf, Memoires Societe Royale des Sciences de Liege, Series 6(10), 141-164, 1976.

Gill., A. E. : Atmosphere-Ocean Dynamics, Academic Press, New York, 662 pp., 1982.

Hellermann, S. and Rosenstein, M.: Normal wind stress over the world ocean with error estimates, J. Phys. Oceanogr., 13, 10931104, 1983.

Karageorgis, A. P., Kaberi, H. G., Tengberg, A., Zervakis, V., Hall, P. O. J., and Anagnostou, Ch. L.: Comparison of particulate matter distribution, in relation to hydrography, in the mesotrophic Skagerrak and the oligotrophic northeastern Aegean Sea, Continental Shelf Research, 23, 1787-1809, 2003.

Kondo, J.: Air-sea bulk transfer coefficients in diabatic conditions, Boundary-Layer Meteorol., 9, 91-112, 1975.

Kontoyiannis, H., Kourafalou, V. H., and Papadopoulos, V.: The seasonal characteristics of the hydrology and circulation in the Northwest Aegean Sea (Eastern Mediterranean): observations and modeling, J. Geophys. Res., 108(C9), 3302, doi:10.1029/2001JC001132, 2003.

Korres, G. and Lascaratos, A.: A one-way nested eddy resolving model of the Aegean and Levantine basins: implementation and climatological runs, Ann. Geophys., 21, 205-220, 2003, http://www.ann-geophys.net/21/205/2003/.

Kourafalou, V. H., Oey, L.-Y., Wang, J. D., and Lee, T. N.: The fate of river discharge on the continental shelf. Part I: modelling the river plume and the inner-shelf coastal current, J. Geophys. Res., 101(C2), 3415-3434, 1996.

Kourafalou, V. H. and Barbopoulos, K.: High resolution simulations on the North Aegean Sea seasonal circulation, Ann. Geophys., 21, 251-265, 2003,

http://www.ann-geophys.net/21/251/2003/.

Kourafalou, V. H., Savvidis, Y. G., Koutitas, C. G., and Krestenitis, Y. N.: Modeling studies on the processes that influence matter transfer on the Gulf of Thermaikos (NW Aegean Sea), Continental Shelf Research, 24, 203-222, 2004.

Lowe, P. R.: An approximating polynomial for the computation of saturation vapor pressure, J. Appl. Meteorol., 16, 100-103, 1977.

Mellor, G. L. and Yamada, T.: Development of a turbulence closure model for geophysical fluid problems, Rev. Geophys. Space Phys., 20(4), 851-875, 1982.

Bungiorno Nardelli, B., Larnicol, G., D’Acunzo, E., Santoleri, R., Marullo, S., and Le Traon, P.Y.: Near Real Time SLA and SST products during 2-years of MFS pilot project: processing, analysis of the variability and of the coupled patterns, Ann. Geophys., 21, 103-121, 2003, http://www.ann-geophys.net/21/103/2003/.

Natale, S., Sorgente, R., Gabersek, S., Ribotti, A., and Olita, A.: Central Mediterranean Sea forecast: effects of high-resolution atmospheric forcings, Ocean Sci. Discuss., 3, 637-669, 2006, http://www.ocean-sci-discuss.net/3/637/2006/.

Nittis, K., Zervakis, V., Papageorgiou, E., and Perivoliotis, L.: Atmospheric and Oceanic observations from the POSEIDON buoy network: Initial results. The Global Atmosphere and Ocean System, special issue - POSEIDON: An Integrated Operational Oceanographic System, Vol. 8, 2-3, pp. 87-99, 2002. 
Nittis, K., Perivoliotis, L., Korres, G., Tziavos, C., and Thanos, I.: Operational monitoring and forecasting for marine environmental applications in the Aegean Sea, Environmental Modelling and Software, 21, 243-257, 2006.

Olson, D. B., Kourafalou, V. H., Johns, W. H., Samuels, G., and Veneziani, M.: Aegean Surface Circulation from a Satellitetracked Drifter Array, J. Phys. Oceanogr., in press, 2007.

Pinardi, N., Allen, I., Demirov, E., De Mey, P., Korres, G., Lascaratos, A., Le Traon, P.-Y., Maillard, C., Manzella G., and Tziavos, C.: The Mediterranean Ocean Forecasting System: First phase of implementation (1998-2001), Ann. Geophys., 21, 320, 2003, http://www.ann-geophys.net/21/3/2003/.

Poulos, S. E., Drakopoulos, P. G., and Collins, M. B.: Seasonal variability in sea surface oceanographic conditions in the Aegean Sea (Eastern Mediterranean): an overview, J. Mar. Syst., 13, 225244, 1997.

Rosati, A. and Miyakoda, K.: A general circulation model for upper ocean circulation, J. Phys. Oceanogr., 18, 1601-1626, 1988.

Smagorinsky, J.: General circulation experiments with the primitive equations, I. The basic experiment, Mon. Wea. Rev., 91, 99-164, 1963.

Sofianos, S. S., Skliris, N., Mantziafou, A., Lascaratos, A., Zodiatis, G., Lardner, R., Hayes, D., and Georgiou, G.: Nesting operational forecasting models in the Eastern Mediterranean: active and slave mode, Ocean Sci. Discuss., 3, 1225-1254, 2006, http://www.ocean-sci-discuss.net/3/1225/2006/.
Therianos, A. D.: Rainfall and geographical distribution of river runoff in Greece, Bull. Geol. Soc. Greece, XI, 28-58 (in Greek), 1974.

Thorpe, S. E., Heywood, K. J., Stevens, D. P., and Brandon, M. A.: Tracking passive drifters in a high resolution ocean model: implications for interannual variability of larval krill transport to South Georgia, Deep-Sea Res. I, 51, 909-920, 2004.

Zervakis, V., Georgopoulos, D., and Drakopoulos, P. G.: The role of the North Aegean in triggering the recent Eastern Meiterranean climate changes, J. Geophys. Res., 105, 26 103-26 116, 2000.

Zervakis, V. and Georgopoulos, D.: Hydrology and Circulation in the North Aegean (eastern Mediterranean) throughout 19971998, Mediterranean Marine Science, 3, 1, 7-21, 2002.

Zodiatis, G. and Balopoulos, E.: Structure and characteristics of fronts in the North Aegean Sea, Boll. Oceanol. Theor. Appl., XI, 113-124, 1993.

Zodiatis, G.: Advection of the Black Sea water in the north Aegean Sea, Global Atmos. Ocean Syst., 2, 41-60, 1994.

Zodiatis, G., Alexandri, S., Pavlakis, P., Jönnson, L., Kallos, G., Demetropoulos, A., Georgiou, G., Theodorou, A., and Balopoulos, E.: Tentative study of flow patterns in the North Aegean Sea using NOAA-AVHRR images and 2D model simulations, Ann. Geophys., 14, 1221-1231, 1996, http://www.ann-geophys.net/14/1221/1996/.

Zavatarelli, M., Pinardi, N., Kourafalou, V. H., and Maggiore, A.: Diagnostic and prognostic model studies of the Adriatic Sea circulation: Seasonal variability, J. Geophys. Res., 107(C1), doi:10.1029/2000JC000210, 2002. 